\title{
Development of Disruptive Growth Engine: Double Cases Study Based on Alibaba and Tencent
}

\author{
Wei LI $^{1}$, Yuchen LEI ${ }^{2}$ and Yutian LIU ${ }^{3}$ \\ 1 Northwest University, Xi'an, China; xbdxlw@126.com; 534625535@qq.com; 2915930624@qq.com \\ * Corresponding author: xbdxlw@126.com
}

\begin{abstract}
Facing the new situation, new problems and new challenges, China firmly implements the innovation-driven development strategy and places scientific and technological innovation at the core of the overall national development. Christensen's disruptive innovation theory provides a theoretical direction for Chinese enterprises to practice the innovation-driven development strategy and break through growth barriers through innovation, Christensen \& Raynor pointed out the future research direction that how to develop a disruptive growth engine to enable enterprises to repeatedly start disruptive business and achieve disruptive growth. Through the double case study of Alibaba and Tencent, this paper answers three questions of how to get the ideas of disruptive innovation, how to shape the ideas of disruptive innovation into disruptive business, and how to make disruptive business achieve disruptive growth, finds out the driving force for enterprises to start disruptive business continuously, and constructs the theory model of disruptive growth engine remembering and responding to Christensen.
\end{abstract}

Keywords: disruptive innovation; disruptive business; disruptive growth engine

JEL Classification: M10; O12; O33

\section{Introduction}

Facing the new situation, new problems and new challenges, China firmly implements the innovation-driven development strategy and places scientific and technological innovation at the core of the overall national development. As the main body of market economy and the main carrier of economic development, enterprises are duty bound to become the main force of innovation-driven development strategy and play a decisive role in market allocation of innovation resources. However, as an emerging economy, how can domestic enterprises, especially those in strategic emerging industries, break through the growth barriers through independent innovation, catch up with and surpass leading enterprises, and play the main role in practicing the innovation-driven development strategy?

Christensen established the theory of disruptive innovation through series of articles and two classic books named the innovator's Dilemma (1997) and the innovator's solution (2003), provided a new idea for emerging enterprises to catch up with and surpass leading enterprises, and also provided a theoretical direction for Chinese enterprises to break through the growth barriers through innovation. Based on the theory of disruptive innovation, Christensen and Raynor (2003) first put forward the concepts of disruptive 
growth and disruptive growth engine in his book named the innovator's solution, that is the process of constantly creating disruptive business, so that enterprises can repeatedly start disruptive business and complete disruptive growth. Although they have not yet found that any enterprise has developed such an engine, they think it is possible, and put forward four key steps to develop destructive growth engine. Under the influence of Christensen \& Raynor, Anthony et al. (2008) tried to develop the process of disruptive growth of enterprises, designed the innovation structure and innovation system of enterprises. Dyer et al. (2011) studied the genes of innovators, that is, the five discovery skills for generating innovative ideas. Silverstein et al. (2012) developed 58 skills and two processes for enterprises to grow through innovation. $\mathrm{Xu}$ and $\mathrm{Li}$ et al. (2014) studied the growth mechanism of enterprises based on disruptive innovation, and found that technology disruption, product disruption, market disruption and service disruption jointly form a disruptive growth engine on the basis of opening the window of technology and market opportunity, launch disruptive attacks on existing industry leaders, constantly occupy their market share, and finally establish new industry competition rules. Brad et al. (2016) studied the lean design method of disruptive innovation. Generally speaking, the research of destructive growth engine is still in the exploratory stage. Under the background of China's innovation-driven development strategy and industrial transformation and upgrading, many enterprises, especially strategic emerging enterprises, will get unprecedented development opportunities and broad space, it has great theoretical value and practical significance to study the disruptive growth engine based on the Chinese context.

Based on the theory of disruptive innovation, this paper selects Chinese case enterprises to study how to get the ideas of disruptive innovation, how to shape the ideas of disruptive innovation into disruptive business, and how to make disruptive business achieve disruptive growth, find out the driving force for enterprises to start disruptive business continuously, and construct the theory model of disruptive growth engine remembering and responding to Christensen, a master of innovation management.

\section{Methodology}

\subsection{Case Selection}

This paper studies how to construct the theory model of disruptive growth engine, which is an exploratory research problem and suitable for case study (Yin, 2014). However, the research problem explored in this paper is neither a universal problem nor an extreme phenomenon, but an interesting business phenomenon. Therefore, based on the principle of theoretical sampling, the method of double case study is adopted. To study a pair of mutually reinforcing cases can reflect and supplement the same phenomenon, and enhance the application of the theory (Eisenhardt, 1989; Mao \& Chen, 2017).

There are three reasons for selecting the research case in the Internet industry. First, the Internet industry has fast innovation and development speed, and there are many business cases of disruptive innovation, especially the cases of repeatedly starting disruptive 
innovation business that are in line with the theoretical sampling are not available in other industries. Second, the competitive structure of the Internet industry is relatively stable, which is convenient for selecting typical cases and collecting data. Third, the development of Internet industry is relatively mature, which is convenient for the correct evaluation of leading enterprises' disruptive innovation business operation and disruptive growth.

The cases studied in this paper should meet the following conditions. First, they are Chinese local enterprises, which is convenient to study the disruptive growth engine based on Chinese context. Second, they are in line with the principle of theoretical sampling, the selected enterprises have obtained the concept of disruptive innovation for several times, and successfully operate the disruptive innovation business repeatedly to achieve disruptive growth. Third, they are in line with the principle of typicality, which can fully show the process of constantly creating disruptive business. Fourth, data is relatively easy to obtain. Based on the above four conditions, this paper selects Alibaba and Tencent as research cases.

\subsection{Case Introduction}

Alibaba was founded in 1999. With the mission to Make It Easy to Do Business Anywhere, it has made intensive efforts in the Internet field and served the development of Chinese small and medium-sized enterprises for a long time. Through a series of disruptive innovation businesses, it has realized the sustained disruptive growth and become a leading enterprise in China's e-commerce industry. So, it is the most typical Chinese case of constructing the theory model of disruptive growth engine. Considering the different levels of development and disruptive degree of Alibaba's business, this paper focuses on 1688, Taobao, and Tmall business in the field of e-commerce, Alipay and Yu'ebao business in the Internet financial field, Cainiao Network in the modern logistics field, and new retail business as the research object.

Tencent was founded in 1998, it has adhered to the business philosophy of User Value is Our Guiding Principle since its establishment. Through a series of imitative innovation of instant messaging software, it has provided consumers with high-quality Internet comprehensive services, and gradually grown into an Internet-based technology and culture enterprise, which has profoundly affected and changed the way of communication and living habits of humanity. Based on the enterprises' disruptive business, this paper focuses on the QQ and WeChat business as the research object.

\subsection{Data Collection}

This paper collects data from various sources and establishes a case database. First, investigated and surveyed Alibaba and Tencent. Second, collected 484 papers about Alibaba and 324 papers about Tencent by CNKI database. Third, bought 12 books about Alibaba and Tencent. Fourth, collected 34 full texts of Jack Ma's public speeches and 27 full texts of Huateng Ma's public speeches. Fifth, collected enterprise information on the official websites of Alibaba and Tencent. 


\subsection{Data Analysis}

This paper adopts single case analysis and comparative analysis between cases. First of all, the paper makes a longitudinal analysis on each case enterprise, straightens out the historical evolution of the enterprise, studies the ideas source, business operation and enterprise growth of each disruptive innovation business of the enterprise, and further studies the driving force of repeatedly starting disruptive innovation business of the enterprise, so as to construct a clear theoretical framework of disruptive growth engine. Secondly, makes a comparative analysis between the two cases for looking for differences and similarities, then constructs a theoretical model.

\section{Results}

Under the guidance of disruptive innovation theory, based on the case study of Alibaba and Tencent, this paper draws the following five conclusions.

\subsection{It Is Feasible to Develop the Disruptive Growth Engine of Enterprises}

On the basis of theoretical research and case study, this paper constructs a theoretical model of disruptive growth engine, as shown in Figure 1. Therefore, based on the case study of Chinese enterprises, it is found that developing disruptive growth engine is feasible, which responds to the expectation of Christensen and Raynor.

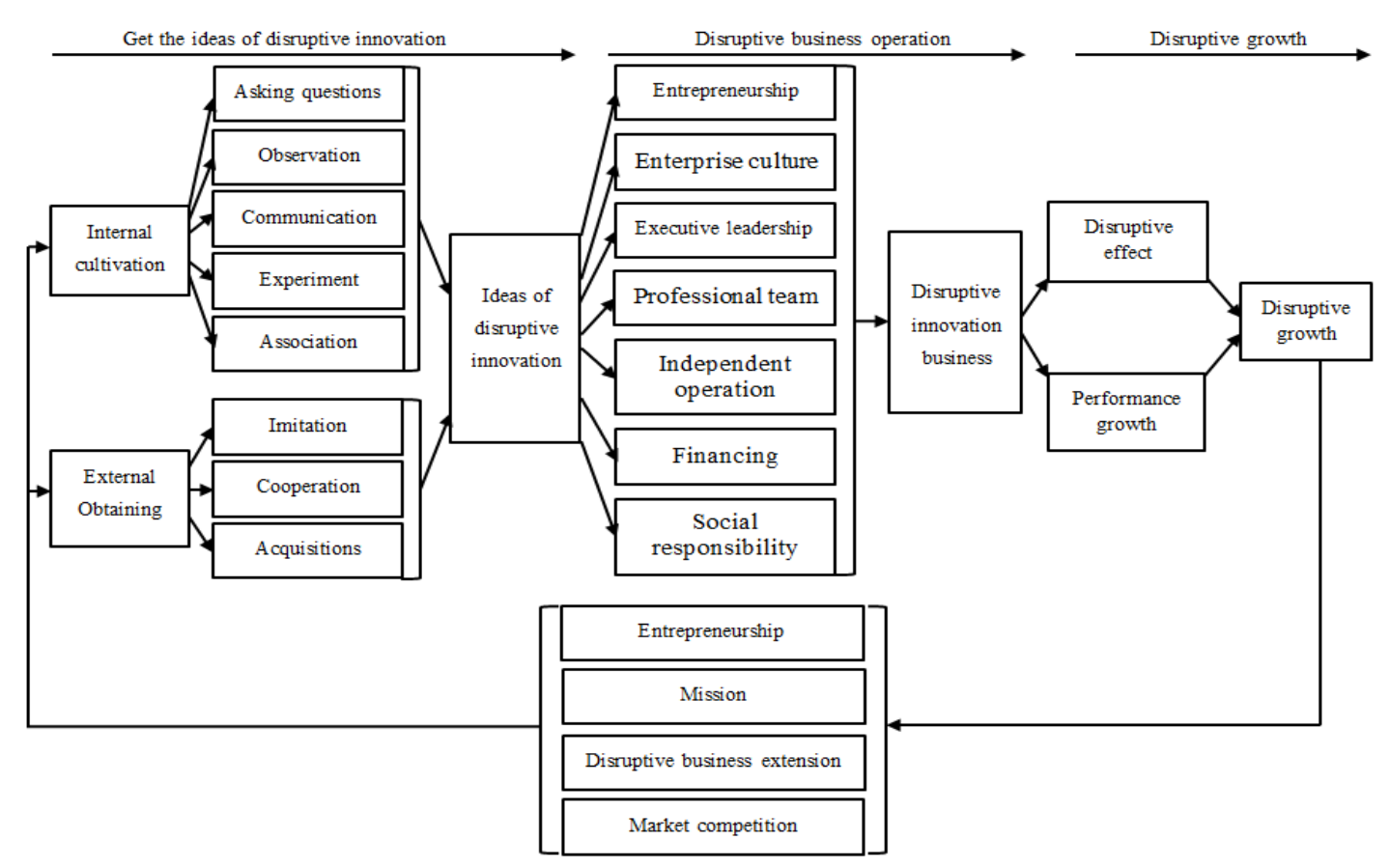

Figure 1. Theoretical model of the disruptive growth engine

\subsection{Disruptive Innovation Ideas Can Come From Both Internal and External Sources}

From the inside, through entrepreneurs and team members repeatedly using the five discovery skills of asking questions, observation, communication, experiment and association, enterprises can cultivate disruptive innovation ideas. From the outside, 
enterprises can also obtain disruptive innovation ideas through imitation, cooperation and acquisitions. In particular, the idea of disruptive innovation is not necessarily original innovation. The practice of Alibaba and Tencent shows that enterprises can Chinese innovate based on imitation, for example, Alibaba's B2C, C2C and Alipay respectively imitate Amazon, eBay and PayPal, Tencent's QQ and WeChat respectively imitate ICQ and $\mathrm{KIK}$, and turn the continuous innovation in mature markets into disruptive innovation in China's emerging markets. In other words, disruptive innovation has the characteristics of market relativity, and the continuous innovation of one market may be the disruptive innovation of another market.

\subsection{The Enterprises Shape Disruptive Innovation Ideas into Disruptive Businesses by Using a Variety of Means}

For enterprises pursuing innovation and growth, the core problem is not the lack of good ideas, the real problem lies in the commercialization process, that is, transforming disruptive innovation ideas into specific business models. Therefore, how to transform disruptive innovation ideas into successful disruptive innovation business under certain conditions is the key to the good operation of disruptive growth engine. From the perspective of Alibaba and Tencent's disruptive innovation business operation, entrepreneurship, enterprise culture, executive leadership, professional team, independent operation, financing and social responsibility are all important conditions for transforming disruptive innovation ideas into disruptive innovation business, a brief description will be given in 4.2. Enterprises can combine their own reality and comprehensively use these means to shape disruptive innovation ideas into disruptive innovation business.

\subsection{The Extension of Disruptive Business can Start New Disruptive Business and Promote the Disruptive Growth of Enterprises}

Business innovation based on disruptive innovation is the extension of the original business, this extension may bring continuous innovation or new disruptive innovation to the enterprise. However, for competitors and consumers, the innovation of enterprises based on the original disruptive innovation business is often another disruptive innovation, because enterprises in their own core track, every small step forward, can get rid of competitors a big step. In other words, disruptive innovation has the subject relativity, and the continuous innovation of disruptive innovation enterprises may be a disruptive innovation for competitors and consumers. Therefore, the extension of the original disruptive innovation business is an important way for enterprises to obtain the disruptive innovation ideas again and successfully operate the disruptive innovation business.

\subsection{Disruptive Innovation Can Trigger Cross-border Disruption}

With the commercialization of the new generation of information technology, disruptive innovation of enterprises can not only produce disruptive effects in their industries, but also trigger cross-border disruptive effects in other fields and industries. For example, WeChat, developed by Tencent, is obviously disruptive to the traditional media 
industry and telecom industry. Therefore, in the future, it is not enough for enterprises to focus only on their own industry, competitors and competition structure, they must always be alert to the impact of cross-border disruptive innovation. Just as China Telecom, China Mobile and China Unicom have been competing with each other for so many years, they suddenly find that Tencent is their real competitor.

\section{Discussion}

\subsection{Get the Ideas of Disruptive Innovation}

- Internal Cultivation

From the perspective of internal cultivation, the five discovery skills of asking questions, observation, communication, experiment and association proposed by Dyer et al. (2011) are very conducive to get the ideas of disruptive innovation, and the discovery skills of enterprise leaders are more important.

Asking Questions. Good questions are the key catalyst to inspire creative thinking. In 1995, Jack Ma first used the Internet through his friend Bill in Seattle, and asked the questions to stimulate his entrepreneurial enthusiasm. Why is there no information about China? Why not create something about China? (Alibaba Group, 2015a; Alibaba Group, 2017). These problems made Jack Ma decide to take the Internet as a breakthrough for entrepreneurship and open Alibaba's Internet business empire. In 1997, Huateng Ma first used the instant messaging software ICQ, which was jointly developed by three Israelites, he was attracted by its infinite charm, but the English version of ICQ is difficult to popularize in China. Huateng Ma asked himself, why not make a Chinese version of ICQ (Guan, 2015). This question aroused Huateng Ma's impulse to start a business and eventually developed the Chinese version of instant messaging software OICQ, which is the predecessor of QQ.

Observation. Disruptive innovators are also diligent observers. They carefully observe the world around them, including markets, customers, products, services, policies and competitors. They not only observe the successful experiences that are worth learning from, but also keenly observe the existing problems and opportunities that can be further improved. Through positive observation, they gain unique insights and ideas.

When Jack Ma first used the Internet in Seattle, he observed that there was no Chinese information on the Internet, which planted the seeds of his entrepreneurship in the Internet field. While working in China's Ministry of Foreign Trade and Economic Cooperation, Jack Ma keenly observed that the Internet wave around the world was coming, so he left Beijing and went back to Hangzhou to start his new business. In 1999, Jack Ma observed that the Asian e-commerce conference, the discussion was mainly about the European and American e-commerce model serving large enterprises, and he also witnessed the difficulties of Chinese small and medium-sized enterprises, so he decided to create an e-commerce model serving small and medium-sized enterprises. In 2002, eBay entered China, which attracted Jack Ma's great attention. He observed all the websites in the world at that time and found that eBay would become Alibaba's biggest challenge. So he launched 
Taobao. By observing the competition between eBay and Amazon and the problems existing in Taobao, Jack Ma realized that B2C is the mainstream of e-commerce, so Alibaba launched Tmall. Jack Ma further observed that lack of credit has become the most serious bottleneck, he launched Alipay which was the third-party online payment platform. The application of Alipay has been widely popularized, and more and more money have been deposited in Alipay's account, which has aroused widespread concern and doubt, so Alibaba launched Yu'ebao. With the rapid development of e-commerce, Jack Ma observed that logistics has become a new bottleneck, so Alibaba launched the Cainiao Network.

After using ICQ, Huateng Ma observed that ICQ was likely to bring about a communication revolution in China, but its English interface and operation didn't conform to the market in China at that time, so he obtained a clear direction of entrepreneurship. In 2010, an application named KIK gained 1 million users within 15 days, Xiaolong Zhang, who was in charge of Tencent's e-mail business, obviously noticed the rapid rise of KIK, but his observation was more profound. What he saw was that the blooming of KIK and KIK-like software was likely to pose a fatal threat to QQ. Therefore, with the support of Huateng Ma, he quickly got the idea of disruptive innovation and launched the WeChat.

Communication. Disruptive innovators are often typical idea communicators, they have a wide range of interpersonal relationships, actively participate in all kinds of idea communication activities, communicate with people with different backgrounds and views, spend time and energy to find and test ideas, so as to get very different views. In Jack Ma's view, after meeting all kinds of people in the world, listening to all kinds of views, and communicating with excellent people, the vision and depth of observing will be very different. When he was a college student, Jack Ma served as the president of the student union and the president of the Hangzhou Federation of Students. And when he was a teacher, he founded the first English corner on the West Lake and established Haibo translation agency. These experiences have trained his skills of communication and organization. Because he knew Bill when he was running Haibo translation agency, he had the opportunity to use firstly the Interne. After leaving school to start a business, extensive communication is an important means for Jack Ma to obtain business ideas. Externally, he actively participates in various conferences, makes friends with heads of state and business leaders of various countries, listens to the voice of customers, and has in-depth communication with the team and employees, which sparks innovation. In the early days of Tencent's, it faced the risk of breaking the capital chain. The founder team of Tencent participated in Chinese international high-tech achievements fair and met Shu Wang, the general manager of IDG, they convinced Shu Wang to invest in Tencent and broke the capital bottleneck.

Experiment. Disruptive innovators are always trying new experiences and new ideas. Unlike scientists, business innovators don't work in the laboratory because the world is their laboratory. Although asking questions, observation and communication can provide data in past and present, for disruptive innovation, there is no data to reference, the best way to collect data is experiment. Just as Jack Ma said, "if you want to do something, action is essential, if you do it, you have a chance to succeed, but if you give it up, it's like thinking 
a thousand ways at night and going the same way in the morning" (Alibaba Group, 2015a). Therefore, every innovative business can't do without experiments. For the establishment of Alibaba and the development of every business, there are no successful experience to learn from, so Alibaba can only grope through experiments again and again. In the initial stage, no one was optimistic about OCIQ, if Huateng Ma gave it up because of others' doubts, if he didn't carry out the business experiment, there would be no QQ and Tencent's business empire. Xiaolong Zhang, the inventor of WeChat, said, "at the beginning, WeChat was not as a strategic project, it was just an experiment, no one knew what the future would be like" (Jiang et al., 2014).

Association. The key skill to form new ideas is association. Disruptive innovators actively explore a wide range of new information and ideas through asking questions, observation, communication and experiment, these methods are important catalysts for association. Disruptive innovators connect their own experiences and integrate them into new ideas. In fact, most of the new things that innovators invent are not real new things, innovators just recombine the ideas in a new way. By actively using the methods, innovators can improve association ability. Innovators collect the more ideas, the more they can get new ideas.

- External Obtaining

Imitation. From $\mathrm{B} 2 \mathrm{~B}$ to $\mathrm{C} 2 \mathrm{C}$, and then to $\mathrm{B} 2 \mathrm{C}$, they are not entirely Alibaba's own innovation, these models are originated in developed market of U.S.A. Alibaba's e-commerce models are essentially imitations, but these imitations are not simple copying, but closely combining these e-commerce models with China's national conditions. So they are Chinese innovation based on imitation and disruptive innovation in China's emerging markets.

Although Tencent has become a global giant, it still can't tear off the label of imitation. The prototype of $\mathrm{OQ}$, WeChat, as well as every value-added service can be found. However, Tencent is growing stronger and stronger by imitation, while the objects been imitated gradually fade out our vision. The key reason is that Tencent's success is not simple imitation too, but the innovation based on imitating, adding new elements of Chinese culture and consumer demand. Huateng Ma believes that imitation is the safest innovation (Zhang, 2013).

To sum up, innovation based on imitation can also lead to disruptive innovation, continuous innovation in a mature market may become disruptive innovation in another emerging market.

Cooperation. The idea of Yu'ebao is not from the internal team of Alibaba, but the cooperation of Alibaba and Tianhong Asset Management Co. Ltd. Cainiao Network is from cooperation of Alibaba and logistics enterprises and warehousing enterprises, and has become an essential infrastructure for Chinese business. Although Hema Fresh, one of the new retail models, was launched by Alibaba, its idea does not come from Alibaba. It was first proposed by Yi Hou, the former head of JD.COM. When Yong Zhang who was Alibaba's CEO and Yi Hou got to know each other, they had a strong ideological resonance, 
so in 2015, Yi Hou left JD.COM and officially joined Alibaba to help Alibaba launch Hema Fresh.

Acquisition. The idea of WeChat comes from Xiaolong Zhang, although the idea is not acquired through acquisition, the innovation team is acquired through acquisition. For Alibaba and Tencent's disruptive innovation, they didn't obtain the ideas directly through acquisition, but this mode is completely possible in theory. As the domestic and even international enterprises that can repeatedly start disruptive business are very rare, we still insist that acquisition is one of the channels for enterprises to obtain disruptive innovation ideas from the outside in the theoretical model.

To sum up, the disruptive innovation ideas of enterprises can be obtained through both internal and external, it is often the result of multiple means working together. Moreover, internal cultivation is the main method, supplemented by external obtaining.

\subsection{Disruptive Business Operation}

How to transform disruptive innovation ideas into successful disruptive business is the key to the disruptive growth engine. From the perspective of Alibaba and Tencent's disruptive business operation, entrepreneurship, enterprise culture, executive leadership, professional team, independent operation, financing and social responsibility are all important conditions for transforming disruptive innovation ideas into disruptive business.

- Entrepreneurship

China needs entrepreneurs, especially entrepreneurship. However, for entrepreneurs who promote disruptive innovation, in addition to the general characteristics of honesty, adventure, cooperation and dedication, they also especially need the entrepreneurship of forward thinking, innovation courage, taking responsibility, never giving up and passion, these characteristics are the most powerful driving force.

- Enterprise Culture

Enterprise culture is enterprises' soul and inexhaustible power. For Alibaba and Tencent, enterprise culture is the driving force for entrepreneurs and employees to work hard, and it is also the rudder of enterprises. No matter how the business environment changes, the two enterprises have never deviated from the values orientation, which is the most important factor for the two enterprises to get disruptive innovation ideas and start disruptive business again and again. Alibaba is an enterprise driven by mission and values (Alibaba Group, 2017), all activities are closely around the mission to Make It Easy to Do Business Anywhere. Jack Ma said, “If you ask where Alibaba's ideas come from, they are come from mission and values" (Alibaba Group, 2015b). All innovative activities of Tencent always start from consumer's demand and value, which is the principle of thinking and operation.

- Executive Leadership

Executives not only play an important role in getting disruptive innovation ideas, but also play an indispensable role in the operation of disruptive business. Executives often 
need to personally operate disruptive business, choose the right time to start disruptive business, coordinate the conflicts between existing business and new disruptive business, allocate resources and deal with emergencies. In short, executives need to use their power and influence to support disruptive business.

- Professional Team

The successful operation of disruptive business also needs a united and efficient team. Jack Ma believes that the most precious wealth of an enterprise is the team and its cohesion. He was pretty confident that it doesn't matter to lose Alibaba or Taobao, as long as the team is still there, he can recreate a miracle (Alibaba Group, 2015b). Huateng Ma also believes that team is the enterprise's biggest asset, the success of an enterprise is never just a matter of money or resources, the key is team (Ma, 2017).

- Independent Operation

Independent operation helps to improve the concentration, flexibility and freedom of disruptive business. Alibaba and Tencent attach great importance to the independent operation of business, and ensure the independence of business. If the organizational structure becomes the constraint of business and restricts the innovation and development, the enterprises will make timely and reasonable adjustments.

- Financing

For disruptive business, sufficient money is related to the successful operation of the business and the survival of the enterprise, especially in the early stage of enterprise. However, not all money is suitable for disruptive business, disruptive business needs the patient money, not the money eager for quick success and instant benefit. Therefore, the choice of what kind of money, when to finance and how to use the money all play a crucial role in the successful operation of disruptive business.

- Social Responsibility

A great company must solve social problems(Alibaba Group,2017). One of the important characteristics of disruptive innovation is the social responsibility. Only strive to solve social problems, the disruptive business can be operated smoothly. For Alibaba and Tencent, one of the important reasons for repeatedly starting and successfully operating disruptive business is that enterprises have implanted social responsibility into the business model. Tencent has taken the social responsibility of improving the quality of human life with technological innovation, completely changed human's living habits, and made outstanding contributions to social development.

\subsection{Disruptive Growth}

- Alibaba's Disruptive Growth

Through successful operation of disruptive business such as 1688, Taobao, Tmall, Alipay, Yu'ebao, Cainiao Network and new retail business, Alibaba has built a new market credit system in China, created a new way of payment, fostered e-commerce industry, 
promoted the vigorous development of Internet finance, modern logistics and other emerging industries, accelerated the transformation and upgrading of traditional industries, forced the reform of the financial system, constructed a national logistics infrastructure, changed the mode of enterprises operation, market competition and human life, promoted China's consumption upgrading and high-quality economic development, and created a new path for China to solve the poverty.

Disruptive business has made Alibaba develop rapidly. The sales in annual Singles' Day of Tmall increased from 52 million Yuan in 2009 to 372.3 billion Yuan in 2020, with an average annual compound growth rate of 124.10 percent (Alibaba Group, 2010-2021). At present, Alibaba ranks first among China top 100 Internet enterprises in 2020, second among Hurun's top 500 private enterprises in 2020, 18th among Fortune's China top 500 in 2020, 132nd among Fortune's world top 500 in 2020, and second among Fortune's 100 companies that will change the world in 2020.

- Tencent's Disruptive Growth

Through QQ and WeChat, Tencent has created China's leading instant messaging platform, made instant messaging, especially WeChat, become an essential infrastructure like water, electricity and highway, deeply affected and changed the communication habits and lifestyle of residents, as well as the business model and environment, so the quality of human life has been effectively improved. Nowadays, instant messaging and a series of value-added services are destroying the business model of telecommunications, media and other traditional industries, even affected China's monetary policy.

Tencent's performance has improved significantly. The revenues and profit have increased respectively from 1.144 billion Yuan and 0.447 billion Yuan in 2004 to 377.289 billion Yuan and 94.351 billion Yuan in 2019, the average annual compound growth rate has reached 43.68 percent and 39.73 percent respectively (Tencent, 2004-2019). The monthly active consumers of QQ has increased from 135 million in 2004 to 727 million in 2019, and the monthly active consumers of WeChat has increased from 355 million in 2013 to 1.165 billion in 2019.

\subsection{Driving Force of Disruptive Growth Engine}

The "engine" needs enough "fuel" to continuously provide power. Through the study on Alibaba and Tencent, it has found that the synergy of entrepreneurship, enterprises mission, extension of disruptive business and market competition makes enterprises have a steady stream of motivation to strive to obtain disruptive innovation ideas from inside or outside and start disruptive business.

- Entrepreneurship

Entrepreneurship is the key driving force of disruptive growth engine. Forward-thinking enables entrepreneurs to see and think things in the next decade or even beyond. As Jack Ma said, "we will start to do what we need in ten years later"( Alibaba Group,2014). Innovation courage makes entrepreneurs not satisfied with the present 
situation, have the courage to break through the boundaries of thinking and the shackles of the environment, and do something that others dare not or can't. The enterprisers taking responsibility integrate social responsibility and their love for the country into the innovation, when the enterprise encounters setbacks, they can stand up and become the navigator of enterprise and the spiritual leader of all employees. Never giving up means that entrepreneurs have firm belief and, no matter what difficulties they encounter, they will never give up. The passion is not only reflected in the entrepreneurial passion and energy, but also can affect everyone around them with passion and positive energy.

- Enterprise Mission

Enterprise mission embodies the value proposition and social responsibility of the enterprise, and is also the lofty goal of enterprise. Alibaba's mission is to Make It Easy to Do Business Anywhere, and Tencent's mission is to Improve the Quality of Human Life Through Internet Services, the important reason for the success of the two enterprises through disruptive innovation is that they not only determine the enterprise mission in line with the social development, but all business must closely around the mission, and any business contrary to the mission has been resolutely abandoned.

- Extension of Disruptive Business

The innovation of Alibaba and Tencent shows that the disruptive growth engine is based on the mission and starting from the first disruptive business. Alibaba's disruptive innovation is gradually extended with e-commerce as the main line, while Tencent's disruptive innovation is gradually extended with instant messaging as the main line. Every innovation of Alibaba and Tencent may be disruptive innovation or continuous innovation for the enterprise itself, but it is disruptive innovation for consumers and competitors. Therefore, the extension based on the original disruptive business is an important way for enterprises to obtain the ideas of disruptive innovation and successfully operate the new disruptive business again.

- Market Competition

Market competition makes enterprises have a strong consciousness of crisis, and forms a forced mechanism for disruptive innovation of enterprises, so that enterprises can get the ideas and start disruptive business by imitation. Alibaba launched Taobao business in response to eBay, Jack Ma said, "We launched C2C to prevent that when eBay enters China, we have no defense capability" (Alibaba Group, 2015b). One of the purposes of Alibaba's launch of Alipay is PayPal, Jack Ma recalled, "Before we launched Alipay, we have realized that if we do not do it now, what shall we do when PayPal enters China in the future?" (Alibaba Group, 2015b). With the rapid rise of KIK, Xiaolong Zhang and Huateng Ma deeply felt the serious threat to QQ. Therefore, Huateng Ma immediately organized three teams to develop WeChat at the same time. It can be seen that, as Jack Ma said, "Most of innovation is not because enterprises want to innovate, but because they have to do" (Alibaba Group, 2017). 


\section{Conclusions}

Christensen \& Raynor (2003) put forward the concept of disruptive growth engine for the first time. However, because there are very few enterprises successfully starting disruptive business continuously, the literature in this field is very rare. Through the double case study of Alibaba and Tencent, this paper answers three questions of how to get the ideas of disruptive innovation, how to shape the ideas of disruptive innovation into disruptive business, and how to make disruptive business achieve disruptive growth, finds out the driving force for enterprises to start disruptive business continuously, and constructs the theory model of disruptive growth engine remembering and responding to Christensen, a master of innovation management.

\section{References}

Alibaba Group. (2015a). Jack Ma's internal speech: Believe in tomorrow. Red Flag Press.

Alibaba Group. (2015b). The age of the Internet has just begun: Jack Ma's internal speech 2.0. Red Flag Press.

Alibaba Group. (2017). Jack Ma: The future has come. Red Flag Press.

Alibaba Group. (2009-2020). Financial Annual Report. https://www.alibabagroup.com/cn/ir/reports.

Anthony S. D., Johnson M. W., Sinfield, J. V., \& Altman E. J. (2008). The innovator's guide to growth: Putting disruptive innovation to work. Harvard Business Press.

Tencent (2019). Financial Annual Report. https://www.tencent.com/zh-cn/investors/financial-reports.html.

Brad, S., Murar M., \& Brad, E. (2016). Methodology for lean design of disruptive innovations. Procedia CIRP, 50(1), 153-159. https://doi.org/10.1016/j.procir.2016.04.204

Cheng, Z. (2013). Tencent: Internet empire created by "taking doctrine". Military Correspondent, 2, 47-48. https://10.13765/j.cnki.cn11-4467/g2.2013.02.031

Christensen, C. M. (1997). The innovator's dilemma: When new technologies cause great firms to fail. Harvard Business School Press.

Christensen, C. M., \& Raynor, M. E. (2003). The innovator's solution: Creating and sustaining successful growth. Harvard Business School Press.

Dyer, J., Gregersen H., \& Christensen C. M. (2011). The innovator's DNA: Mastering the five skills of disruptive innovators. Harvard Business School Press.

Eisenhardt, K. M. (1989). Building theories from case study research. Academy of management review, 144, 532-550. https://doi.org/10.5465/amr.1989.4308385

Jiye, M., Cheng, C. (2017). Theoretical construction of case study: Eisenhardt's new insight. Management World, 2, 135-141. https://doi.org/10.19744/j.cnki.11-1235/f.2017.02.012

Jiuxiang, X., Hua, L., \& Chunyuan, W. (2014). Research on enterprise growth model based on disruptive innovation. Science of Science and Management of S.E T, 35(2), 134-142.

Hongjun, J., Shulong, H., \& Xiumin, F. (2014). Xiaolong Zhang: WeChat brings new challenges to the world. Business Research, 20, 28-39.

Huateng, M. (2017). I started Tencent these years. Chinese \& Foreign Entrepreneurs, 22, 4-6.

Lan, G. (2005). Huateng Ma: The father of Tencent QQ. Management E Technology of SME,2005, 9, 12-13.

Silverstein, D., Samuel, P., \& Decarlo, N. (2012). The innovator's toolkit: 50+ techniques for predictable and sustainable organic growth (2nd ed). Management Group International.

Yin, K. (2014). Case study research: Design and methods 5th ed. Sage Publications, Inc. 